\title{
A Estratégia da Transferência na Psicanálise como Contradispositivo
}

\author{
Márcia Cristina Maesso* \\ Universidade de Brasília, Brasília, DF, Brasil
}

\begin{abstract}
RESUMO - A noção de dispositivo, desenvolvida na filosofia política, abrange formas estratégicas complexas que atuam no exercício do poder intervindo no processo de subjetivação. O objetivo deste estudo teórico é contribuir para a clínica dos sofrimentos psíquicos, através dos fundamentos conceituais, éticos e políticos da psicanálise, reguladores da direção do tratamento. Na discussão, consideramos o manejo da transferência como estratégia que opera no sentido oposto ao do dispositivo, como contradispositivo, chegando à conclusão de que a transferência tem relação com o poder, mas sua condução estratégica, mantendo no horizonte a falta fundamental, possibilita o surgimento de algo novo na repetição, a entrada do acaso, do real, como efeito do ato analítico no discurso.
\end{abstract}

PALAVRAS-CHAVE: transferência, repetição, dispositivo, contradispositivo, ética

\section{The Strategy of Transference in Psychoanalysis as a Counter-Device}

\begin{abstract}
The notion of device, developed in political philosophy, covers complex strategic methods that act in the exercise of power intervening in the subjectification process, and was, therefore, addressed in this theoretical study, whose goal is to contribute to the psychic suffering practice, through psychoanalysis conceptual, ethical and political fundamentals, all directional regulators of treatment. In the discussion, we considered the management of transference as a strategy that operates in opposite direction to said device, a counter-device, concluding that transference has a relation with power, yet its strategic conduction, considering the fundamental flaw, enables the emergence of something new in the repetition, the input of the random, of the real, as an effect of the analytical act in the discourse.
\end{abstract}

KEYWORDS: transference, repetition, device, counter-device, ethics

A transferência, como fenômeno clínico, deteve a atenção de Freud desde os primórdios da psicanálise. Isso emerge no trabalho teórico-clínico realizado no início da fundação do campo psicanalítico, intitulado Estudos sobre a histeria, no qual ele denominou de falsa ligação o envolvimento do psicanalista nos afetos que foram vividos pelo analisante no passado e que se tornavam presentes no tratamento psíquico (Freud, 1895/1980). A palavra alemã Übertragung, traduzida por transferência e utilizada por Freud para nomear o fenômeno, abrange conotativamente "um arco que mantém aceso o processo de ida e vinda" (Hanns, 1996, p. 412), podendo atuar sobre a temporalidade, no trânsito entre o passado e a atualidade, sobre a espacialidade, com o movimento entre o longe e o perto, e através da passagem de uma pessoa a outra. A acepção da palavra alemã faz jus ao que Freud considerou, ao longo de sua extensa obra, a respeito da estreita relação da transferência com a repetição na situação analítica, evidenciando que, embora a transferência produza obstáculos na forma de resistência ao tratamento ou ao seu fim, ela também propicia acesso ao inconsciente, tornando-o atual. Portanto, seu manejo se estabelece como condição indispensável para a realização do tratamento psicanalítico (Freud, 1912/2017).

Depois de Freud, outros psicanalistas se debruçaram sobre o tema da transferência e produziram desdobramentos teóricos e clínicos, dentre os quais destacaremos, no escopo deste estudo, as contribuições de Jacques Lacan, posto que estas resultaram na criação de novas formulações sobre a transferência que ultrapassaram as que foram feitas por Freud sem, contudo, contradizê-las. Os aportes teóricos

\footnotetext{
*E-mail:maessomc@gmail.com

- Submetido: 10/10/2019; Revisado: 21/01/2020; Aceito: 25/03/2020.
} 
de Lacan (1958/1998, 1959/1997, 1964/1973) enfatizaram a ética como condição para o manejo da transferência na direção da cura e culminaram na sua elevação à categoria de conceito fundamental da psicanálise, portanto serão tomados como referência na articulação que propomos realizar acerca dos elementos que envolvem a transferência e suas relações com o poder na direção do tratamento psicanalítico.

A despeito das diferenças entre as fundamentações de Freud e de Lacan sobre a transferência, encontramos na ética da psicanálise um eixo comum, eixo no sentido de suporte, de sustentação, que concerne à tangibilidade da transferência na clínica psicanalítica. Ao situar a ética como o eixo regulador do manejo transferencial, tanto Freud quanto Lacan estiveram atentos aos riscos de que o método psicanalítico enveredasse para uma prática do poder, tamanha a tentação que envolve querer saber o que é o bem, para fazer o bem ao outro. Lacan (1958/1998) apontou que há um princípio maligno no direcionamento cego do poder de fazer o bem ao outro, formulando, com proveito da ambiguidade do sentido, a seguinte frase, na qual aproxima o poder ao fazer o bem: "É o poder de fazer o bem - nenhum poder tem outro fim, e é por isso que o poder não tem fim" (Lacan, 1958/1998, p. 647). Saber o que é o bem e fazer o bem, implica em sobrepor ao sujeito, os ideais fomentados em distintas sociedades, culturas e épocas, por meio de dispositivos que o conduz a tomar como verdade as definições e determinações sobre o bem, inviabilizando sua autonomia quanto a ponderar e inventar o que é o bem para si, na forma de viver, gozar e desejar.

Isso posto, enunciamos o objetivo de alcançar, ao longo do presente estudo teórico, contribuições para a prática clínica dos sofrimentos psíquicos, envolvendo leitura e discussão a respeito da articulação entre os fundamentos conceituais, éticos e políticos da psicanálise, na função de regular a práxis do psicanalista, na direção do tratamento e da cura. Buscaremos circunscrever, à luz das proposições de Freud e de Lacan, o raciocínio de que o manejo da transferência no tratamento psicanalítico, em um trabalho orientado para produzir a autonomia do sujeito, opera como um contradispositivo de poder, considerando primordial a sustentação da ética da psicanálise, como condição para a condução estratégica e para a execução da técnica no decurso do tratamento.

A noção de dispositivo, desenvolvida na filosofia política, abrange formas e estratégias complexas que atuam no exercício do poder e são intervenientes no processo de subjetivação, portanto será abordada nesse estudo, cujo objetivo é o de contribuir para o tratamento clínico dos sofrimentos psíquicos, ressaltando que os fundamentos epistemológicos, éticos e políticos constituídos campo psicanalítico sustentam a condução estratégica do tratamento, promovendo uma práxis que visa operar no sentido contrário ao do dispositivo.

\section{DISPOSITIVO E PODER}

O termo dispositivo não é uma noção ou conceito da psicanálise, como aponta a pesquisa de Checchia (2010), situando que ele aparece poucas vezes e com conotações distintas na obra de Freud, e nas raras vezes que Lacan o utilizou, não o fez em referência à psicanálise. Na única vez que Lacan (1972/2003) mencionou o termo dispositivo relacionando-o ao discurso psicanalítico, o fez definindo-o como o que toca o real, para além do inconsciente, cuja formação se atrela ao simbólico. Tomemos essa menção feita por Lacan ao dispositivo, a fim de considerar no decurso desse texto, a preponderância da ética da psicanálise no manejo da transferência e na condução do tratamento: “... a questão não é a descoberta do inconsciente, que tem no simbólico sua matéria pré-formada, mas a criação do dispositivo pelo qual o real toca no real, ou seja, daquilo que articulei como o discurso psicanalítico" (p. 545).

O termo dispositivo foi abordado na filosofia política, primeiramente por Michel Foucault, em diversos dos seus trabalhos de forma dispersa, posteriormente por Gilles Deleuze (1996) e por Giorgio Agamben (2005) a partir de uma entrevista concedida por Foucault (1977/2017), na qual apresentou uma conceitualização sobre o que é um dispositivo. Essa entrevista foi publicada na revista Ornicar em 1977 com o título Le Jeu de Michel Foucault, mas, pode ser lida na seção Sobre a história da sexualidade no livro Microfisica do poder (Foucault, 1977/2017). Vejamos um fragmento da longa resposta de Foucault sobre o sentido e a função do termo dispositivo:

um conjunto decididamente heterogêneo que engloba discursos, instituições, organizações arquitetônicas, decisões regulamentares, leis, medidas administrativas, enunciados científicos, proposições filosóficas, morais, filantrópicas. Em suma, o dito e o não dito são os elementos do dispositivo. O dispositivo é a rede que se pode estabelecer entre esses elementos. (p. 364)

Na sequência da entrevista, Foucault (1977/2017) aborda que o dispositivo tem função estratégica, sendo essa uma característica marcante na definição que ele faz: "É isto, o dispositivo: estratégias de relações de força sustentando tipos de saber e sendo sustentadas por eles". (p. 367). A proposta aqui não é a de enveredar em uma análise filosófica do dispositivo, mas, tão somente, abordar o que essa noção abarca e circunscrever brevemente a função social e subjetiva que exerce, com o intuito de considerar que o manejo da transferência, na situação psicanalítica, intenta funcionar como um contradispositivo de poder. 
Na citada entrevista, Foucault (1977/2017) definiu o dispositivo de modo amplo, destacando que se trata de uma rede que se estabelece entre o dito e o não dito que circula nas criações, nas mais diversas instituições, sendo composto de um conjunto heterogêneo com a função estratégica de manipular as relações de força, visando uma determinada direção. Os apontamentos e contribuições de Deleuze (1996), a partir do que foi proposto por Foucault, evidenciam que os dispositivos funcionam na condução do sujeito a um fim deliberado pelos detentores do poder, destacando que são como máquinas de fazer falar por meio dos enunciados e máquinas de fazer ver pela projeção de uma luz que não ilumina de forma geral os objetos preexistentes, mas que se propaga distribuindo e determinando o visível e o invisível. A interpretação de Agamben (2005) da complexa definição formulada por Foucault envolve o argumento de que um dispositivo é tudo o quanto possa exercer a função de "capturar, orientar, determinar, interceptar, modelar, controlar e assegurar os gestos, as condutas, as opiniões e os discursos dos seres viventes" (Agamben, 2005, p. 13). O autor considera que há uma evidente conexão de algumas instituições com o poder, tais como os manicômios, prisões, fábricas, escolas, igrejas, disciplinas, panóptico, entre outras, e destaca outros dispositivos, cuja relação de poder se faz de forma obscura, como a literatura, escritura, filosofia, agricultura, cigarro, computadores, celulares e a linguagem, que é apontada como o mais antigo dos dispositivos.

Há concordância nos comentários dos autores supramencionados a respeito da análise feita por Foucault sobre a sociedade disciplinar, ao longo de sua obra e na entrevista de 1977, situando que o dispositivo também implica em um processo de subjetivação para que seja um dispositivo de governo, caso contrário, seria uma prática da violência (Agambem, 2005; Deleuze, 1996). Consonante a isso, haveria uma relativa condescendência no processo de assujeitamento, que de acordo com Agamben (2005), estaria culminando num processo de dessubjetivação que se relaciona com as características da sociedade capitalista atual. A saída da condição de sujeição, apontada por Agamben, seria a profanação como contradispositivo, pois considerando o sacrifício como o dispositivo que "faz a passagem de alguma coisa profana para o sagrado" (p. 14), que regula a separação do que concerne à esfera humana ao fazer a transferência para o divino, a profanação é o contradispositivo que devolve ao uso comum o que havia sido separado pelo sacrifício.

Partindo das proposições de Foucault (1977/2017) e Agamben (2005), Checchia (2010) afirma que a clínica psicanalítica é um dispositivo, posto que sua composição corresponde à definição foucaultiana de dispositivo, porque está formada como um conjunto composto de elementos heterogêneos, quais sejam, associação livre, transferência, diagnóstico, silêncio, interpretação, o tempo da sessão e o pagamento, que estariam organizados na estratégia e na tática que, por sua vez, são subordinadas à política e à ética da direção do tratamento. Entretanto, se a clínica psicanalítica é um dispositivo em razão de sua composição, não sustenta nem é sustentada por um saber apriorístico conjugado ao poder que conduz à sujeição. Pelo contrário, como se apoia em uma epistemologia fundamentada no compromisso com a prevalência da ética e da política no direcionamento do tratamento, o saber é concebido como não todo e como uma produção do sujeito, a posteriori. Nessa via de raciocínio, Checchia (2010, p. 99) considerou a possibilidade de o dispositivo psicanalítico funcionar como um "contradispositivo de profanação".

Concordando com o argumento de que a clínica psicanalítica funcione como um contradispositivo, indagamos sobre quais elementos e por quais meios, estaria a serviço de exercer a profanação. Ousamos responder que trata-se do saber sobre o desejo e o gozo, que foi delegado ao Outro, concebido como consistente detentor do poder e do saber absoluto. É o saber, que deve ser restituído ao sujeito, por meio do tratamento do real pelo simbólico que a psicanálise propõe, não como saber sem furos, mas como saber fazer algo novo, criar, inventar, servindo-se da falta fundamental em si e no Outro.

O poder divino, supremo, representado pelo clericalismo, foi relativizado, profanado pela ciência e pelas artes no período do movimento renascentista, marcando o advento da modernidade. Entretanto, contraditoriamente, isso resultou, ao longo da história, na passagem do poder soberano ao poder disciplinar, diluído e invisível, ao mesmo tempo que gerou uma crise subjetiva, porque a ruptura com as determinações imputadas pela tradição, colocou o homem moderno diante do desamparo de não saber sobre seu destino, tendo de lidar com a nostalgia do saber e do poder sagrado que foram supostamente perdidos, pois na verdade nunca existiram, apenas foram divinizados (Kehl, 2002; Figueiredo \& Santi, 2013; Freud, 1930/2010; Foucault, 1975/1987). Nesse contexto histórico, brevemente apontado, evidenciou-se o mal-estar do homem moderno na sociedade ocidental, sua divisão subjetiva, que fomentou o surgimento da psicanálise como via de tratamento do sofrimento psíquico, incluindo em seu método, de modo original, o manejo da transferência, norteado pelos princípios da ética do desejo e do bem dizer.

Freud (1980/1912) observou que a transferência tem relação com o poder em função da neurose, do recalque diante da afirmação da castração do Outro, declarando que o fenômeno da transferência não é responsabilidade da psicanálise, sendo que nas instituições pode haver formas indignas de transferência que, sem tratamento psicanalítico, chegam à servidão. Isso coaduna com o raciocínio de Foucault (1977/2017, p. 371) de que "as grandes estratégias de poder se incrustram", porque as condições de seu exercício estão situadas nas "microrrelações de poder". Uma análise acontece por meio da microrrelação estabelecida entre dois, em posições díspares, a transferência implica poder 
pela suposição do saber no analista, mas em decorrência desse tratamento, cujo método envolve o manejo ético da transferência como um dos seus pilares, pode-se alcançar uma mudança de posição do sujeito, respeitante às formas de poder exercidas em várias outras relações sociais.
Partindo dessas considerações, propomos articular três elementos que envolvem a práxis da psicanálise: a ética, que está relacionada à política; a transferência, que está relacionada à estratégia; e a técnica, que está relacionada aos modos de intervenção.

\section{TRANSFERÊNCIA, ÉTICA E TÉCNICA}

Tomando a formulação de Foucault (1977/2017) de que o dispositivo envolve fundamentalmente a estratégia de relações de poder voltada para uma direção preestabelecida, buscaremos abordar, do conjunto heterogêneo que compõe a clínica psicanalítica, o manejo da transferência como contradispositivo de poder, em razão de a transferência criar condições para que aconteça uma psicanálise, implicar suposição de saber, por conseguinte de poder, e estar diretamente relacionada com a estratégia da direção do tratamento.

A clínica psicanalítica não se sustenta em bases procedimentais, não há códigos de conduta ou deontológicos, muito menos há manuais que determinem como deve ser a prática do psicanalista na aplicação da técnica. Mas, isso não resulta em dizer que haja uma completa liberdade no exercício da função do psicanalista, pois ele deve responder a uma posição ética como condição de execução da técnica, que por sua vez, deve ser a realização da ética. Ética e técnica estão imbricadas no método de tratamento psicanalítico, na condução estratégia que envolve e é envolvida pela transferência.

A proposição de Freud sobre a transferência, em sua articulação à técnica, comparece nos Estudos sobre a histeria (1895/1980), nos casos clínicos que ele publicou, e de forma mais adensada junto aos artigos nos quais se dedicou a tratar especificamente da questão técnica, que estão reunidos no período de 1911 a 1915, quais sejam: O manejo da interpretação dos sonhos na psicanálise (1911/1980); Dinâmica da transferência (1912/1980); Recomendações ao médico para o tratamento psicanalítico (1912/2017); Sobre o início do tratamento (1913/2017); Recordar, repetir, elaborar (1914/1980); Observações sobre o amor transferencial (1915/2017) e anos depois, no texto $A$ análise finita e a infinita (1937/2017). Não abordaremos todos os artigos mencionados, mas, de modo geral, os textos técnicos nos quais Freud fez suas considerações sobre a transferência, com o objetivo de destacar que tais considerações estão imbuídas de caráter ético.

Muitos anos antes de escrever os textos técnicos, Freud (1905/2017) havia afirmado, no artigo intitulado Sobre psicoterapia, que a psicanálise se orienta numa via oposta à do método da sugestão que é praticado nas psicoterapias. Nesse artigo, Freud mencionou as fórmulas de Leonardo da Vinci respeitantes ao contraste entre os métodos usados na pintura e na escultura, para expressar a diferença entre o método psicanalítico e o da sugestão. Nessas fórmulas, $\mathrm{o}$ artista situa que a pintura procede per via di porre, em um trabalho que acrescenta a tinta sobre a tela em branco, enquanto a escultura se faz per via di levare, subtraindo as pedras até que a estátua surja. Freud aproximou o método psicanalítico da escultura que "retira da pedra o necessário para revelar a estrutura da estátua nela contida" considerando que, de forma oposta, nas psicoterapias, aplica-se a sugestão "para impedir a ideia patogênica de se expressar". (Freud, 1905/2017, p. 67). Com a metáfora da escultura, consideramos que Freud apontou a função do método psicanalítico de retirar a resistência que impede o acesso ao saber inconsciente. Além disso, o método que envolve a fala em associação livre atribui o poder de saber ao sujeito, considerando que ele advirá na articulação dos significantes na cadeia. É na transferência de um significante ao outro significante que surge o saber inconsciente.

Os artigos técnicos são breves e sem regras rígidas, mas Freud é enfático quanto à advertência ética de que o psicanalista não deve ceder à ambição terapêutica e educativa, que configurariam um exercício de poder contrário à proposta de tratamento. $\mathrm{O}$ furor sanandi pode ser entendido como a pressa em eliminar o sintoma, que foi criticada por Freud, porque reduz o tempo necessário para o analisante realizar o devido trabalho psíquico e por ser o sintoma um meio de semi-dizer a verdade.

A técnica que Freud propõe segue a regra fundamental da psicanálise da associação livre, que funciona como uma lei à qual tanto o analisante, quanto o analista devem se submeter. Do lado do analista, a escuta psicanalítica em atenção flutuante, coaduna com a associação livre, fazendo flutuar o sentido, respeitando o tempo de constituição do saber do sujeito, a posteriori. O exercício da regra fundamental e o tempo que lhe é requerido são necessários para evitar a sobreposição dos conceitos ou saberes científicos previamente estabelecidos, como chave de leitura diagnóstica a ser usada na seleção do que é relevante para o tratamento, ou numa pretensa revelação da verdade subjacente ao sintoma. Freud (1912/2017) considerou que apesar de pesquisa e tratamento coincidirem no trabalho analítico "a técnica que serve a um, de certo ponto de vista, acaba se opondo à outra", pois, em função de respeitar o saber do sujeito a devir, "não é bom abordar um caso cientificamente enquanto o respectivo tratamento não tiver sido concluído" (p. 97). Honrar a regra fundamental da associação livre não é apenas solicitar que, ao falar, o analisante evite escolher o conteúdo mais importante para 
o andamento do tratamento, é especialmente escutar sem a preocupação de lembrar, deixando em suspensão a atenção deliberada (Freud, 1912/2017).

No artigo Recordar, repetir, elaborar, Freud (1914/1980) tratou da diferença entre a repetição pela atuação (agieren) na esfera motora e a repetição na esfera psíquica, desejável que ocorra no espaço artificial criado na transferência com o analista. O sintoma analítico, artificial, produzido em transferência, é acessível à intervenção do psicanalista. A repetição na psicanálise implica elaboração e renovação por meio do trabalho psíquico, que consiste na decifração viabilizada pela fala na situação instaurada pela transferência, situação que faz ressoar o dizer do sujeito naquilo que é dito. A rememoração já é uma atividade de leitura interpretativa, Freud considerou que as lembranças não se referem exatamente ao fato ocorrido, elas podem, inclusive, ser criações encobridoras.

A técnica psicanalítica sofreu transformações com o avançar das construções lógico-conceituais exigidas pela experiência clínica. Freud (1914/1980) distinguiu três momentos e os motivos implicados nessas mudanças. No primeiro momento, com auxílio da hipnose, a técnica visava à ab-reação, reprodução dos processos mentais envolvidos na formação do sintoma, a rememoração ocorria pela hipnose. No segundo momento a hipnose foi abandonada, instaurou-se a regra fundamental da associação livre, meio pelo qual o analista poderia interpretar o que o paciente deixava de recordar e oferecer-lhe o resultado da interpretação que girava em torno dos elementos formadores do sintoma. No terceiro momento, equivalente à nova técnica criada por ele, a associação livre, o foco sobre o sintoma foi abandonado, não era mais demandado ao paciente falar sobre os acontecimentos que possivelmente o teria provocado, mas falar sobre qualquer assunto que lhe viesse à cabeça, sem censura prévia. Coerentemente à proposta de condução de tratamento estabelecida a partir da terceira e última alteração da técnica, a escuta do psicanalista não deveria privilegiar nenhum assunto com a finalidade de decifrar o sintoma, não deveria seguir uma meta prescrita, mas dedicar-se à atenção equiflutuante.

Como declarou Freud (1914/1980), apesar das mudanças técnicas, o objetivo permaneceu o mesmo, qual seja, o de preencher as lacunas na memória superando as resistências e a barreira do recalque. Portanto, o motivo de havê-las mudado corresponde à transferência com a qual Freud se deparou, notando que alguns de seus pacientes faziam rememoração como se estivessem hipnotizados pelo analista e outros atuavam em vez de recordar, servindo-se da transferência como meio de resistência ao tratamento. Freud estava atento quanto à irrealidade da idealização e do amor erigidos em torno da figura do analista, assim como concebia que eram respeitantes à posição de submissão do paciente em relação ao poder de saber que, ele próprio, por eximir-se de enfrentar a castração, atribuía ao terapeuta. Advertido disso, ele se absteve de ocupar, de se identificar com a posição de saber e poder que lhe era designada, privilegiando tratar a transferência no âmbito psíquico (Freud, 1915/2017). Isso posto, consideramos que a última técnica, mantida até os nossos dias, revela a sutileza da escuta de Freud em concordância com sua posição ética, incidindo na condução estratégica do tratamento, ou seja, no manejo da transferência, buscando com essa alteração, na qual o analista é responsável por fazer operar a regra fundamental da psicanálise, manter na "esfera psíquica", por meio do bem dizer, o que poderia ser dirigido à "esfera motora" (Freud, 1914/1980, p. 200).

Nessa via da escuta em atenção flutuante, privilegiada por Freud na situação transferencial, encontramos elucidativas formulações de Lacan no decurso de sua obra, vamos tocar em algumas. Em Função e campo da fala e da linguagem em psicanálise, Lacan (1953/1998, p. 256) aponta que a escuta psicanalítica, como atenção difusa ou distraída, não supõe um "objeto para-além da fala do sujeito", mas um objeto simbólico na atualidade dessa fala, na qual se manifesta o passado, revertido na repetição, possível pela com-temporalidade da transferência. A rememoração é o passado na fala, é passar o passado para o verbo, para o epos, poema, tendo como consequência nessa passagem ao simbólico, o seu esvanecimento, considerando a função antitética da palavra, como presença que guarda a ausência, como meio de criação de realidades, mas também de matar a coisa.

No seminário sobre a ética da psicanálise, Lacan se referiu à obra de Aristóteles, Ética a Nicômaco, para formular que enquanto o Bem Supremo aristotélico, que é a felicidade, está colocado como a finalidade da ação, como ideal ético a ser alcançado, para a psicanálise os limites éticos coincidem com os limites de sua práxis (Lacan, 1959/1997). Essa práxis se fundamenta na tática, na estratégia e na política, como Lacan (1958/1998) definiu no relatório A direção do tratamento e os princípios de seu poder, escrito em data muito próxima ao seminário sobre a ética. Nesse relatório Lacan considerou que a aplicação da regra analítica, a associação livre, que é igualmente sua técnica, se desdobra em uma complexidade de elementos. Ele apontou que a transferência se refere à implicação política do analista, que deve estar posicionado em relação a sua falta-a-ser, ou seja, advertido da própria castração e da castração do Outro. O psicanalista conduz o tratamento, mas não conduz o analisando como guia moral e a direção do tratamento consiste "em fazer com que o sujeito aplique a regra analítica" (Lacan, 1958/1998, p. 592). A escuta psicanalítica é ética ao possibilitar ao sujeito se inventar e formular sua verdade por meio da fala em associação livre, do relato do sonho, da criação do chiste, do ato falho, do sintoma, da mentira, enfim, de diversos modos de formação do inconsciente, concebidos como semi-dizer do sujeito. Com efeito, Lacan (1958/1998) salientou que cabe ao analista fazer o analisando esquecer que se trata, ou seja, que se cura, apenas de palavras, mas que disso o analista 
jamais deve se esquecer. O poder da palavra, da associação livre, é o único ao qual a dupla envolvida no tratamento deve se submeter.

O psicanalista institui-se a partir de sua práxis orientada pela ética em relação ao real e não em relação ao ideal de conduta moral ou de cura a ser alcançada, sendo preciso abster-se do poder entranhado no querer fazer o bem. Essa orientação implica em uma política que alude à sua faltaa-ser e culmina no desejo do psicanalista de que o sujeito surja por meio da cadeia de significantes, pelo material produzido no simbólico, pelas formações do inconsciente passíveis de serem decifradas, sendo esse o meio pelo qual se torna possível produzir uma abertura para tocar o real. $\mathrm{O}$ procedimento de interpretação coaduna com a política de falta-a-ser do analista, visando criar algo novo ao propor o significante no advento do significado, considerando que a estrutura do inconsciente é homóloga à da linguagem (Lacan, 1958/1998).

Lacan (1959/1997) se refere à ética aristotélica para contornar a questão da ética na psicanálise, mas evidencia sua oposição. Enquanto Aristóteles pressupõe uma finalidade da ação, definida pelo encontro da felicidade, para Lacan a ação não encontra seu fim, mas sua continuidade numa cadeia de significantes que substitui o significado. Junto a isso ele propõe que, por meio da demanda de felicidade que se repete na situação analítica e justamente porque ela não é alcançada, o desejo pode ser vislumbrado, considerando que, com a falta de resposta à demanda, o desejo pode ser formulado. Sendo assim, a ética do desejo e a ética do bemdizer são outros nomes para a ética da psicanálise.

\section{UM LUGAR PARA TIQUÊ EM AUTÔMATON}

A ética na psicanálise é posta em relação ao real desde o Projeto para uma Psicologia Científica, trabalho no qual Freud (1950[1895]/1980) considerou a origem do desamparo dos humanos no início de sua existência e a inevitável dependência da ajuda alheia na experiência de satisfação das necessidades. O bebê está subordinado aos cuidados do outro para realizar as funções que o mantém vivo e o humaniza. A alimentação, a higienização do corpo, a interpretação da dor e do incômodo que a criança manifesta pelo choro, bem como várias outras ações exercidas pela imprescindível ajuda alheia, também são geradoras de prazer e atravessadas pela cultura, resultando na fonte de todos os motivos morais e do paradoxo que consiste na erotização do corpo da criança e posterior interdição desse prazer, efetuados pelo mesmo agente. Tal paradoxo, estabelecido no princípio das relações humanas, é respeitante à questão da ética que foi desenvolvida no campo da psicanálise e incide na direção do tratamento, pois condiciona o manejo da transferência considerando sua estreita relação com a repetição que, por sua vez, envolve a busca insistente de um gozo perdido. Lacan (1959-60/1997) abordou a contradição enunciada por Freud (1950[1895]/1980) no Projeto, destacando que, com a formulação sobre o princípio do prazer, Freud derrubou e inverteu a lei moral, mostrando que não há Bem Supremo, pois ele corresponde a das Ding, à mãe, ao objeto do incesto, ao que é proibido.

A noção de das Ding, na psicanálise, aponta para o que, no real, está desde sempre perdido, que jamais pode ser encontrado, nem simbolizado. Portanto a proibição, o sentimento de impotência diante do fracasso constatado nas tentativas de atingir o ideal, ou a insatisfação quanto ao que foi idealizado depois de alcançado, funcionam como recobrimento para o impossível, posto que o reencontro da Coisa (das Ding) é inalcançável como um gozo real. O gozo de das Ding teria existido na forma de um mito, criado após a entrada do sujeito no campo da linguagem, como um paraíso perdido e jamais frequentado. A proposição ética feita por Lacan (1959-60/1997) é de que a busca pelo reencontro de das Ding seja levada a um trilhamento que se faz na passagem de um significante ao outro significante, abalizado pela lei do princípio do prazer que impõe rodeios, descontinuidades entre prazer e desprazer, conservando a Coisa distante do fim que motiva o percurso.

Essa distância assegura o desejo, há apenas (des) encontro, ou seja, há encontro com um objeto instituído na fantasia do sujeito, mas não deixa de ser um encontro falhado, desencontrado, permitindo um gozo parcial, pois no real, a Coisa é intangível. Destarte, podemos formular que a ética da psicanálise é a ética do desejo, porque se fundamenta na advertência quanto à impossibilidade de alcançar o Bem Supremo, outro nome de das Ding, atentando para a improbabilidade das promessas de alguns dispositivos, de conduzir o sujeito a um gozo pleno, sem faltas.

Há relação entre a busca do encontro do Bem Supremo com o pedido de tratamento que é feito ao psicanalista. A demanda, sempre de amor, como Freud (1912/1980) observou precocemente em sua práxis, não pode ser gratificada, tão pouco frustrada, não concerne ao psicanalista, nem a ninguém, essa possibilidade, mas a demanda pode ser trabalhada na direção da revelação do desejo, através da interpretação. Revelar o desejo difere de determinar o seu objeto, pelo contrário, é apontar a falta do objeto, dada sua parcialidade em relação à satisfação do desejo. No seminário anual sobre a transferência, Lacan (196061/1992) ocupou-se do discurso sobre Eros, o Amor, proferido no Banquete (Platão, 1983), para formular sobre a "metáfora do desejante" no decurso do tratamento, ou seja, a passagem do desejado, que é o amado (érôménos) ou desejável, que é o amável (érôménon), ao desejante que posiciona-se como amante (érastès). Sendo a metáfora uma figura de linguagem que acusa a substituição de um termo por outro, com prevalência do sentido, Lacan nomeou como 
metáfora do desejante no amor, a substituição do desejado pelo desejante, posição que antes estava reservada para o outro, de acordo com a demanda de ser amado. Portanto, a metáfora do desejante implica numa mudança de posição, de transferência do lugar de objeto do desejo do outro para a posição de sujeito desejante.

No Banquete, que foi um simpósio sobre Eros, destacase como a demanda de amor foi retratada no discurso de Aristófanes e como Sócrates articulou seu discurso abordando o desejo (Platão, 1983). Aristófanes discursou sobre o mito dos seres andróginos e esféricos aos quais nada faltava, poderosos, eles desafiaram o poder Divino e obtiveram como como castigo a separação de seu corpo em duas partes, desde então, passaram a buscar insistentemente a metade perdida e quando ocorria o encontro, as duas partes pereciam num abraço mortal. O discurso de Sócrates, que se fez através de uma estrangeira por ele inventada e a quem chamou Diotima, foi tecido em exaltação ao belo, envolvendo o desejo de imortalidade na criação e na procriação. Podemos considerar que a morte do desejo comparece no encontro das partes separadas do ser esférico, na ausência da falta, como foi relatado no discurso de Aristófanes, enquanto o desejo de imortalidade, implicando em (pro)criação, em movimento de passagem ao novo, foi apresentado no discurso de Sócrates. Os dois discursos apontam para a dicotomia entre demanda e desejo que surge na situação analítica, na transferência.

A passagem da demanda de amor ao Outro, de ser amado (érôménos), desejado, na posição de objeto, para tornar-se desejante (érastès), na posição de sujeito, se verifica por meio da repetição na cadeia de significantes. A transferência cria condição para que ocorra o irremediável da repetição, que concerne a constatar a cada vez, a impossibilidade do encontro total com o objeto e a incompletude do Outro, num gozo parcial. A repetição que a transferência possibilita, implica em algo novo, entrada do acaso, de tiquê, como efeito do ato analítico, no discurso organizado na cadeia de significantes, autômaton. A repetição é provocada pela prática da psicanálise, cuja estratégia aponta o encontro faltoso por preconizar a fala, "na análise, a repetição é elevada à dignidade de real" (Soler, 2013, p. 111), o analista não responde a demanda de amor, não frustra, nem gratifica, mas revela o desejante.

O acaso, tiquê, remete ao imprevisível, ao "encontro do real", foi desse modo que Lacan (1964/1973, p. 56) propôs traduzir essa palavra, emprestada de Aristóteles, para diferenciar de autômaton, palavra usada para designar a "insistência dos signos aos quais nos vemos comandados pelo princípio do prazer", princípio que visa manter a estabilidade ao conservar os intervalos entre prazer e desprazer, no nível simbólico. Para Lacan (1964/1973, p. 56), "o real é o que vige sempre por trás do autômaton", com isso, atribui à tyché, a função do real como encontro faltoso, como fenda relacionada ao traumatismo. Lacan (1974, p. 57) desdobrou a noção de traumatismo, fundamentada por Freud, criando o neologismo troumatisme para remeter o traumático ao furo, trou, considerando que há um resto do real que permanece inabordável e que constitui o fator traumático para o sujeito. Freud (1896/1980) partiu da hipótese de que o trauma, gerador da neurose, era factual, mas logo a abandonou para chegar à sua teoria da neurose a partir da construção da fantasia em torno do sexual concebido como traumático. A passagem da hipótese do trauma sexual como um fato vivido, para a hipótese do sexual como traumático, tem relação com o que resta inacessível a respeito do sexual. Sendo assim, Freud (1919/2016) formulou o conceito das fantasias originárias ou protofantasias, e as dividiu em fantasia de sedução, castração e cena primária, todas são respeitantes ao enigma da origem, passível de ser tocado apenas por meio de uma construção simbólico-imaginária. Como apontou Jorge (2010, p. 239), cada uma das fantasias originárias está relacionada a um aspecto do enigma da origem: "a da cena primária, com a origem do indivíduo; a da sedução, com a origem da sexualidade; a da castração, com a origem da diferença sexual".

A construção da fantasia está relacionada com a perda de gozo de Das Ding, perda que é fruto da operação do recalque originário, tendo como resultado a possibilidade de um gozo apenas parcial. O gozo parcial envolve a perda de Das Ding, dito de outra forma, a castração do Outro resulta no gozo do resto, dos objetos pulsionais, objeto $a$, que Lacan abordou, ao longo de sua obra, considerando distintas funções, como objeto causa do desejo ou como objeto mais de gozar, dependendo da posição que envolve o sujeito na relação, mas sempre aludindo ao perdido, à falta. Por conseguinte, a fantasia é construída para dar um contorno ao real e atribuir uma cor singular ao objeto $a$, fixando-o, recobrindo-o com um significante prenhe de sentido, como tinta colocada numa tela em branco. Por conseguinte, o trabalho de escuta e leitura das formações do inconsciente, respeitado no campo psicanalítico, como produção de saber, instaura brechas no sentido fixado pela fantasia, gerando recursos para o sujeito inventar algo novo. É um trabalho que se faz na microrrelação estabelecida na situação analítica, que depende de o manejo da transferência estar regulado pela ética da psicanálise e pela política que remete o analista a sua falta-a-ser (Lacan, 1958/1998). O discurso de Sócrates (Platão, 1983) tecido pela boca de uma mulher estrangeira, aponta para sua posição em relação à política da falta-a-ser, ele abdicou do saber que lhe foi suposto pelos convivas, para deixar falar o feminino, o estrangeiro, o inconsciente. 


\section{À GUISA DE CONCLUSÃO}

$\mathrm{O}$ argumento que estabelece a correspondência da clínica psicanalítica à definição foucaultiana de dispositivo remete à sua composição heterogênea e organização estratégica. Tal raciocínio conduziu a formular que a clínica psicanalítica funcione como contradispositivo de profanação, considerando que o dispositivo seja definido sobretudo pela estratégia, a qual na clínica psicanalítica implica no manejo da transferência a partir de uma relação de submissão à ética do desejo e à política da falta- a-ser, como condição para a direção do tratamento. Embora não tenhamos abordado neste estudo, vale ressaltar que uma das finalidades do tratamento consiste na destituição do psicanalista da posição de suposto saber como produto do trabalho do sujeito (Agamben, 2005; Checchia, 2010; Foucault, 1977/2017; Lacan, 1958/1998).

A clínica psicanalítica envolve uma estrutura similar à clínica médica da qual se desdobrou, notadamente, pela ruptura e subversão do campo instaurado por Freud, correspondente ao novo método de investigação e tratamento, por ele criado. A despeito de a psicanálise articular semiologia, etiologia, diagnóstica e terapêutica, o faz caminhando no sentido inverso da clínica médica, que parte da semiologia em direção a formular o diagnóstico com hipóteses etiológicas, para depois propor o tratamento (Dunker, 2011). A psicanálise é uma práxis, começa pela terapêutica e pela transferência. A semiologia, formada pelos fundamentos teóricos e metodológicos, não considera o sintoma como signo da doença, não estabelece relação entre o sintoma e um referente localizado no organismo ou num código pré-estabelecido para conduzir a interpretação por quem sabe como proceder com a sua leitura. É na consideração da instabilidade e da singularidade da relação entre significante e significado na produção da significação, que consiste a possibilidade de leitura do sintoma na psicanálise (Lacan, 1966/1998), em uma semiologia existente no próprio (contra)dispositivo do tratamento, composta pela fala do sujeito, sempre atualizada, repetida, na situação transferencial. Quanto à concepção etiológica, evidencia-se a subversão da psicanálise nas formulações sobre o trauma, sobre as fantasias originárias e nas distintas acepções do objeto a (causa de desejo, objeto pulsional, mais-de-gozar), presentes na obra de Lacan, com destaque para sua característica fundamental de ser faltoso e estabelecer-se na estrutura fantasmática do sujeito (Dunker, 2011; Jorge, 2010). O diagnóstico acontece em uma temporalidade diversa do que é praticado na clínica médica, podendo ocorrer da primeira à última sessão, ou mesmo após o término do tratamento, porque considera a conexão retroativa da intervenção terapêutica e a posição do sujeito na transferência (Maesso, 2013).

A terapêutica é associada ao próprio método de tratamento definido como "método de escuta e intervenção sobre a fala, mas também como método de leitura da escrita que constitui a materialidade do inconsciente" (Dunker, 2011, p. 439). A escuta em atenção flutuante no método de tratamento psicanalítico é a condição da fala, portanto, o meio que permite uma direção à cura (Lacan, 1958/1998), não como restabelecimento da saúde pelo silêncio dos órgãos, como é visado na medicina, ou pela remissão do sintoma, embora isso também possa acontecer, mas como uma talking cure, termo que pode ser traduzido ao pé da letra, no gerúndio, como "falando cura", o que remete ao envolvimento de todo percurso de uma psicanálise em relação à cura. A atenção flutuante, como também a associação livre, fazem o sentido flutuar, permitindo intervenções criativas, pois a interpretação a partir da técnica do significante, brinca com o sentido poético, mas também com a falta de sentido, pelo jogo sonoro e pelo equívoco, propondo a profanação do sentido, como a criança que transforma a função utilitarista de um objeto qualquer, ao fazer dele um brinquedo (Agamben, 2007; Lacan,1957-58/1999).

A clínica psicanalítica é regulada pela ética, não está submetida a uma deontologia, nem à imposição dos dispositivos que conduzem aos ideais sociais e culturais que determinam as condutas e julgam saber o caminho garantidor do encontro de das Ding. A ética na psicanálise se orienta pelo real, de modo que na psicanálise há uma coincidência entre os limites éticos e os limites da práxis, sendo esse o meio pelo qual se concebe tocar o real (Lacan, 1959/1997).

Lacan (1964/1973) propôs elevar a transferência à categoria de conceito fundamental da psicanálise, possibilitando articulá-la aos outros três conceitos, repetição, inconsciente e pulsão que ele também considerou como fundamentais e que apontam para o real, para sustentar a práxis, sempre inédita, porque se trata de verificá-la caso a caso. Com esse passo fez avançar a psicanálise na direção de operar como um "dispositivo pelo qual se toca o real no real” (Lacan, 1972/2003, p.545). Em concordância a essa consideração, Lacan não deixou recomendações sobre o que se deve ou não fazer em um tratamento psicanalítico, nem estabeleceu regras quanto ao ensino dos fundamentos conceituais da psicanálise. Ele fez aportes teóricos para sustentar uma transmissão que conta com o trabalho criativo do sujeito, manifestando sua oposição à concepção de que a formação do psicanalista iniciante seja baseada na identificação ao analista experiente e tomado como ideal.

$\mathrm{Na}$ articulação entre os conceitos fundamentais, o inconsciente está relacionado à presença do analista, portanto envolve a transferência: "a presença do analista é ela própria a manifestação do inconsciente" (Lacan,1964/1973, p. 121). Desse modo, o analista teria a função de se posicionar como testemunha do inconsciente, pois a interpretação do analista apenas recobriria a interpretação já feita pelas formações do inconsciente. Citemos Lacan (1964/1973): “o jogo do significante em suas formações no sonho, lapso, chiste ou sintoma já procedeu por interpretação.” (p. 125). Propondo 
que o inconsciente tenha estrutura homóloga à da linguagem, Lacan (1958) sustentou a tese de que é na estrutura da linguagem que o inconsciente se produz, do lado de fora, na palavra, que mesmo mentirosa, suscita a verdade do sujeito.

A função do psicanalista de dirigir a análise implica em fazer operar a regra fundamental da associação livre, servindo-se do poder e saber que lhe é suposto, transferido, para fazer trabalhar o inconsciente e franquear a passagem do érôménos ao érastès. O poder do tratamento está na sua condução para o poder da palavra, transfere-se para a palavra, o saber suposto no psicanalista, portanto a ética da psicanálise está relacionada com o desejo do psicanalista de que surja o sujeito na cadeia significante, sendo assim considerada como ética do bem dizer e do desejo. Em razão disso, Lacan (1958/1998) concebeu que o analista também tem que pagar no decurso do tratamento, ele paga com palavras, porque elas ganham efeito de interpretação, paga deixando de fora "o que há de essencial em seu juízo mais íntimo" (p. 593) e paga com sua pessoa, que ele empresta como suporte na transferência. Lacan também assinalou que o psicanalista é menos livre em sua política, que envolve a sua posição diante da falta-a-ser, do que em sua estratégia de manejo da transferência e sua tática de interpretação. Entretanto, em função da reflexão que articulamos, concluímos que, embora haja alguma liberdade do psicanalista quanto à estratégia no manejo da transferência e à tática de interpretação, essa liberdade está referida ao compromisso ético e político constituído na sua formação por meio do contradispositivo psicanalítico.

Buscamos propor, ao longo do presente estudo, que os fundamentos éticos orientados pelo real, regulam o método e envolvem os conceitos psicanalíticos, funcionando como advertência quanto ao manejo da transferência que, por sua vez, implica na direção do tratamento e, portanto, da cura, fazendo operar um contradispositivo de poder. Considerando e almejando que essas reflexões possam trazer contribuições, não apenas para a clínica psicanalítica, onde muito se discute a respeito, mas que possam alcançar outros modos de microrrelação, que ocorrem em outros espaços, como escolas, consultórios médicos, entre outros, seria preciso indagar: o manejo da transferência, como contradispositivo de poder, poderia operar fora do (contra)dispositivo psicanalítico? Essa questão requer desdobramentos teóricos e clínicos futuros que também possam abordar o que não foi possível abarcar no presente estudo, concernente aos processos de subjetivação diante dos dispositivos atuais de poder.

\section{REFERÊNCIAS}

Agamben, G. (2005). O que é um dispositivo? Outra Travessia, 5, 9-16. https://periodicos.ufsc.br/index.php/Outra/article/ view/12576/11743

Agamben, G. (2007). Elogio da profanação. In Profanações (pp. 58-71). Boitempo Editorial.

Deleuze, G. (1996). O mistério de Ariana. Vega - Passagens.

Dunker, C. I. L. (2011). Estrutura e constituição da clínica psicanalítica: Uma arqueologia das práticas de cura, psicoterapia e tratamento. Annablume.

Checchia, M. A. (2010). A clínica psicanalítica é um dispositivo? A Peste, 2(1), 89-100.

Figueiredo, L. C. M., \& Santi, L. R. (2013). Psicologia, uma (nova) introdução: Uma visão histórica da psicologia como ciência ( $3^{\mathrm{a}}$. ed.). EDUC.

Foucault, M. (1987). Vigiar e punir: Nascimento da prisão $\left(25^{\mathrm{a}}\right.$ ed.). Vozes. (Original publicado em 1975)

Foucault, M. (2017). Sobre a história da sexualidade. In Microfísica

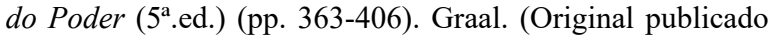
em 1977)

Freud, S. (1980). A etiologia da histeria. In Edição standard brasileira das obras psicológicas completas de Sigmund Freud (vol. 3, pp. 177-203). Imago. (Original publicado em 1896)

Freud, S. (1980). Estudos sobre a histeria. In Edição standard brasileira das obras psicológicas completas de Sigmund Freud (vol. 2, pp. 17-296). Imago. (Original publicado em 1895[1893])

Freud, S. (1980). Projeto para uma psicologia científica. In Edição standard brasileira das obras psicológicas completas de Sigmund Freud (vol. 1, pp. 387-529). Imago. (Original publicado em 1950[1895])

Freud, S. (2017). Sobre a psicoterapia. In Obras incompletas de Sigmund Freud (vol. 6, pp. 63-79). Autêntica. (Original publicado em 1905[1904])
Freud, S. (1980). Fantasias histéricas e sua relação com a bissexualidade. In Edição standard brasileira das obras psicológicas completas de Sigmund Freud (vol. 9, pp. 161170). Imago. (Original publicado em 1908)

Freud, S. (1980). O manejo da interpretação dos sonhos na psicanálise. In Edição standard brasileira das obras psicológicas completas de Sigmund Freud (vol. 12, pp. 119127). Imago. (Original publicado em 1911)

Freud, S. (1980). Dinâmica da transferência. In Edição standard brasileira das obras psicológicas completas de Sigmund Freud (vol. 12, pp. 131-143). Imago. (Original publicado em 1912)

Freud, S. (2017). Recomendações ao médico para o tratamento psicanalítico. In Obras incompletas de Sigmund Freud (vol. 6, pp. 93-106). Autêntica. (Trabalho original publicado em 1912)

Freud, S. (2017). Sobre o início do tratamento. In Obras incompletas de Sigmund Freud (vol. 6, pp. 121-149). Autêntica. (Original publicado em 1913)

Freud, S. (1980). Recordar, repetir e elaborar. In Edição standard brasileira das obras psicológicas completas de Sigmund Freud (vol. 12, pp. 191-203). Imago. (Original publicado em 1914)

Freud, S. (2017). Observações sobre o amor transferencial. In Obras incompletas de Sigmund Freud (vol. 6, pp.165-182). Autêntica. (Original publicado em 1915[1914]).

Freud, S. (2016). Bate-se numa criança: Contribuições para o estudo da origem das perversões sexuais. In Obras incompletas de Sigmund Freud (vol. 5, pp. 123-153). Autêntica. (Original publicado em 1919)

Freud, S. (2010). O mal-estar na civilização. In Obras completas (vol. 18, pp. 13-122). Companhia das Letras. (Original publicado em 1930)

Freud, S. (2017). A análise finita e a infinita. In Obras incompletas de Sigmund Freud (vol. 6, pp. 315-364). Autêntica. (Trabalho original publicado em 1937) 
Hanns, L. A. (1996). Dicionário comentado do alemão de Freud. Imago.

Jorge, M. A. C. (2010). Fundamentos da psicanálise de Freud a Lacan: A clínica da fantasia (vol. 2). Zahar.

Kehl, M. R. (2002). Sobre ética e psicanálise. Companhia das Letras.

Lacan, J. (1998). Função e campo da fala e da linguagem em psicanálise. In Escritos (pp. 238-324). Jorge Zahar. (Original publicado em 1953)

Lacan, J. (1999). O seminário livro 5: As formações do inconsciente. Jorge Zahar. (Trabalho original publicado em 1957/1958)

Lacan, J. (1998). A direção do tratamento e os princípios de seu poder. In Escritos (pp. 591-652). Jorge Zahar. (Origina publicado em 1958)

Lacan, J. (1998). Do sujeito enfim em questão. In Escritos (pp. 229-237). Jorge Zahar. (Original publicado em 1966)

Lacan, J. (1997). O seminário livro 7: A ética da psicanálise. Jorge Zahar. (Original publicado em 1959/1960)
Lacan, J. (1992). O seminário livro 8: A transferência. Jorge Zahar. (Original publicado em 1960-1961)

Lacan, J. (1973). O seminário livro 11: Os quatro conceitos fundamentais da psicanálise. Jorge Zahar. (Original publicado em 1964)

Lacan, J. (1998). O seminário livro 15: O ato analítico. Centro de Estudos Freudianos do Recife. (Original publicado em 1968)

Lacan, J. (2003). ...Ou pior - Relatório do seminário de 1971-72. In Outros Escritos (pp. 544-549). Jorge Zahar. (Original publicado em 1972)

Lacan, J. (1974). Aula de 19/02/1974. In Le non-dupes errent (pp. 54-59). http://staferla.free.fr/S21/S21\%20NON-DUPES....pdf

Maesso, M. C. (2013). O diagnóstico, seu avesso e a posição do psicanalista. Juruá.

Platão. (1983). O banquete. In J. C. Souza (Trad.), Coleção os pensadores. Abril Cultural.

Soler, C. (2013). A repetição na experiência analítica. Escuta. 